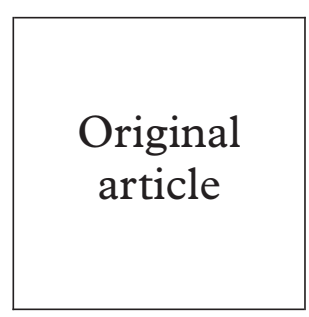

\title{
Neonatal herpes prevention: a minor public health problem in some communities
}

\author{
A Mindel, J Taylor, R L Tideman, C Seifert, G Berry, K Wagner, J Page, C Marks, \\ $\mathrm{B}$ Trudinger, A Cunningham
}

Background: Neonatal herpes is a condition with high morbidity and mortality. The greatest risk occurs when the mother acquires herpes simplex virus (HSV) towards the end of pregnancy. A study from Seattle has suggested that the risk of acquisition of HSV during pregnancy was 3.7\%. In Australia, HSV-2 infection is less common in pregnant women than in the United States. Consequently we conducted a study to establish HSV seroprevalence and the rate of HSV seroconversion in this population.

Methods: The study was conducted at Westmead Hospital, Sydney, between June 1995 and April 1998. Women completed a questionnaire covering risk factors for the acquisition of genital herpes. A serum sample during pregnancy and a specimen of cord blood were obtained and tested for antibodies to HSV-2 using a type specific indirect enzyme linked immunosorbent assay (ELISA). Equivocal results were resolved by western blot. A subset of the paired sera was tested for antibodies to HSV-1. The data were analysed using sPSS.

Results: 326 of the $2616(12.5 \%)$ women were HSV-2 seropositive. Three women $(0.15 \%)$ acquired HSV-2 infection during pregnancy. None of the three babies of these mothers developed neonatal herpes. 416 maternal cord pairs were tested for HSV-1 antibodies and $330(79.3 \%)$ were positive. No HSV-1 seroconversions occurred.

Conclusions: In this population, HSV acquisition was uncommon $(0.34 \%$ per year) and neonatal herpes was rare. A cost effective analysis suggested that type specific serology to screen pregnant women and their partners in low prevalence communities was not cost effective. (Sex Transm Inf 2000;76:287-291)

Keywords: type specific serology; herpes simplex virus; neonatal herpes

\section{Academic Unit of Sexual Health Medicine, Sydney, Australia \\ A Mindel \\ R L Tideman \\ K Wagner \\ J Page \\ C Marks}

Centre for Virus Research Westmead Institutes of Health Research, Sydney

J Taylor

C Seifert

A Cunningham

Department of Public Health and

Community Medicine,

University of Sydney

G Berry

Department of Obstetrics and Gynaecology

Westmead, Hospital, Universities of Sydney and New South Wales B Trudinger

Correspondence to: Professor Mindel, Academic Unit of Sexual Health

Medicine, Level 1,

Nightingale Wing, Sydney

Hospital, GPO Box 1614,

Sydney, NSW 2001,

Australia

bbeaton@ mail.usyd.edu.au

Accepted for publication 20 March 2000

\section{Introduction}

Neonatal herpes is a devastating condition. Even with treatment the majority of infants will die or be left with severe neurological sequelae. ${ }^{1}$ Fortunately the condition is uncommon with an estimated incidence of up to $50 / 100000$ live births in some parts of the United States, ${ }^{2}$ 6/100000 in Sweden, ${ }^{3}$ 8/100 000 in Australia, ${ }^{4}$ and 3/100 000 in the United Kingdom. ${ }^{5}$

The greatest risk to the neonate of contracting herpes occurs when the mother acquires genital herpes during pregnancy, particularly if this occurs towards or at the end of the third trimester. ${ }^{6}$ A recent study from Seattle suggested that the maternal risk of herpes simplex virus (HSV) type 1 or 2 acquisition during pregnancy was $3.7 \%$ for women who were HSV seronegative and $1.7 \%$ for HSV-2 in those who were initially $\mathrm{HSV}-1$ seropositive. ${ }^{7}$ The results of this study and the observation that the prevalence of HSV-2 infection has increased by $30 \%$ in American adults over the past two decades ${ }^{8}$ have prompted some authors to recommend the use of serological testing in couples considering pregnancy to detect those at risk. This would enable women who are HSV-2 seronegative with an $\mathrm{HSV}-2$ seropositive partner to use condoms or abstain from intercourse during pregnancy. ${ }^{7}$ The feasibility of this approach and its cost effectiveness has not been tested and the impact of this approach on the incidence of neonatal herpes is likely to be minimal. ${ }^{9}$

The prevalence of HSV-2 infections varies enormously in different geographic locations, and in different populations. ${ }^{10}$ The risk of HSV acquisition during pregnancy may be dependent on several factors including HSV-2 and possibly HSV-1 prevalence in the community, the proportion of women considering pregnancy or who become pregnant who are HSV-2 negative, and sexual behaviour during pregnancy. Limited information from pregnant women in Australia ${ }^{11}$ has suggested that HSV-2 infection is less common than in some parts of the United States ${ }^{6-12}$ and this may explain the differences in the incidence of neonatal herpes.

Consequently, we conducted a study to establish HSV-1 and HSV-2 seroprevalence, the factors associated with HSV acquisition and the HSV seroconversion rate in a large hospital in Sydney, Australia, where HSV-2 seroprevalence was lower than Seattle.

\section{Subjects and methods}

STUDY SETTING

The study was conducted in the obstetric department at Westmead Hospital. This is a large teaching hospital situated in the western suburbs of Sydney, which services a multicultural population. The women were recruited from antenatal clinics between June 1995 and April 1998. Antenatal clinics were run every weekday. However, owing to limited staff avail- 
ability, recruitment occurred on 2 and sometimes 3 days per week. Whenever possible, we tried to recruit during the busiest clinics.

\section{STUDY PROCEDURES}

A research assistant approached women in the waiting room. The nature of the study was explained, written informed consent obtained, and the women were asked to complete a questionnaire covering risk factors for the acquisition of genital herpes (including age, age at coitarche, lifetime number of sexual partners, and history of genital herpes). The questionnaire was available in several languages (English, Arabic, Chinese, and Vietnamese) to cater for the diverse ethnic population attending Westmead Hospital. In some cases non-English speaking patients completed the questionnaire with the assistance of a professional interpreter allocated by the hospital. In other cases non-English patients were assisted by an accompanying friend or relative.

Serum samples were obtained from the serology laboratory from excess serum previously or concurrently taken for syphilis and rubella serology usually during the first trimester. To determine HSV seroconversion during pregnancy a specimen of cord blood was obtained from routine samples taken at the time of delivery. Paired samples were used to test for HSV antibodies and to establish HSV seroconversion.

HSV TESTING

Sera (maternal and cord blood) were stored at $-20^{\circ} \mathrm{C}$ and tested for antibodies to HSV-2 using an indirect enzyme linked immunosorbent assay (ELISA) specific to glycoprotein G2 (gG2). ${ }^{16}$ The assay has levels of sensitivity and specificity of greater than $98 \% \cdot{ }^{16}$ Equivocal ELISA results were resolved by western blot. ${ }^{17}$ Seroconversion during pregnancy was defined as an HSV-2 negative maternal serum sample and an HSV-2 positive cord blood sample. All seroconversions were confirmed by western blot testing.

A subset of the paired sera (maternal and cord) were selected and tested for antibodies to HSV-1. We selected every fifth cord specimen with an available matching maternal specimen. Depending on the HSV-2 serostatus of these sera they were tested by the Behring ELISA for the detection of total antibody to HSV (if HSV-2 negative) or by western blot (if HSV-2 positive). ${ }^{17}$ This strategy was used because of the current lack of a low cost, low labour intensive, accurate ELISA for antibody to HSV-1.

DATA ENTRY AND ANALYSIS

The data from the questionnaires, and the serological results were entered onto a database and analysed using sPss. ${ }^{18}$ Statistical analysis used included descriptive and comparative tests including Pearson's $\chi^{2}$ and Student's $t$ test.

\section{Results}

During the period of the study 13372 women delivered babies at the hospital; 7560 women attended on days when recruiting occurred, of which 3706 (49\%) agreed to participate.
Serum was available for HSV testing on 2616/ $3706(70.6 \%)$ women who completed the questionnaire; 2040 cord blood samples were available from the group of 2616 participants. It was these 2040 mother cord pairs that were included in the seroconversion analysis. There were several reasons for lack of availability of maternal serum including no specimen taken, specimen processed at another laboratory, and insufficient serum remaining after routine syphilis serology and loss or mislabelling of specimen. Some of the women who were being managed privately had serum processed at other laboratories. All of the local laboratories were approached on several occasions to obtain serum samples. However, this approach only yielded a handful of specimens over an 18 month period. Consequently this approach was dropped and only women attending Westmead Hospital for their antenatal care and serology were included. Reasons for lack of cord blood included specimen not taken, insufficient serum, loss of specimen, and the woman delivering at another hospital.

In order to determine how representative our sample was, we compared the demographic, sexual, and obstetric characteristics of all the women who attended antenatal clinics on the days when recruitment occurred but did not participate (3861) with those who were recruited (3706). Participants were significantly younger than the unrecruited women (28.0 (SD 5.3) years and 31.2 (5.4) years respectively, $\mathrm{p}<0.001)$. There was a significant difference in country of birth for recruited and unrecruited women $(p=<0.001)$. Sixty five per cent of the recruited women were born in Australia compared with only $48 \%$ of the unrecruited group and fewer recruited women were born in North or South East Asia (10.5\% compared with $24.4 \%$ ) and the Middle East (6.1\% compared with $9.7 \%$ ). The mean gravidity of recruited women was 2.0 (SD 1.5) compared with 3.0 (1.6) for unrecruited women. However, most of this difference occurred as a consequence of a small number of high gravidity women in the unrecruited group. Similar differences were seen with regard to parity. The mean parity for both groups was 1.0 , but a small number of highly parous women in the unrecruited group resulted in a significant difference between them $(p<0.001)$. The final difference related to whether participants were public or private patients. Eighty four per cent of recruited women were seen in the public sector compared with $67 \%$ of the unrecruited women $(\mathrm{p}<0.001)$.

A total of $326(12.5 \%)$ women were HSV-2 seropositive at the time of their enrolment to the study. On univariate analysis HSV-2 seropositivity was correlated with age, country of birth, age of first sexual intercourse, lifetime number of sexual partners, previous sexually transmitted diseases, having a partner with herpes, educational status, parity, and gravidity.

Although age, ethnic, and other factors were significantly different between recruited and unrecruited patients the actual differences in HSV-2 seropositivity associated with the fac- 
tors were small with the exception of public versus private status. For example, $11.5 \%$ of women from Australia and New Zealand were HSV-2 positive compared with $12.2 \%$ of those from North and South East Asia and 9.2\% of those from the Middle East. However, $12 \%$ of public patients were HSV-2 positive compared with $6.3 \%$ of the private patients. An anonymous unlinked study of HSV-2 seroprevalence in 300 consecutive antenatal admissions during the study showed $12.6 \%$ were HSV-2 positive, similar to that of the recruited women.

Three of the $1746(0.17 \%)$ HSV-2 susceptible women (that is, those who were initially HSV-2 negative) had an HSV-2 seroconversion during the pregnancy (fig 1 ). The average duration between antenatal and cord blood was 182.8 days giving a risk of HSV-2 acquisition of $1.72(95 \%$ CI $0.35-5.02)$ per 1000 women or 3.43 (95\% CI $0.71-10.0)$ per 1000 woman years.

The first baby born to a woman who had an HSV-2 seroconversion during pregnancy was a healthy female baby born vaginally at 41.5 weeks and discharged from hospital 5 days later. The 30 year old gravida 4 para 2 mother had chronic active hepatitis due to hepatitis C. The second baby was born to a 23 year old G2 P0 mother. Again a healthy baby girl was delivered vaginally at 42.2 weeks and discharged 4 days later. The final baby was born to a 24 year old G2P1 mother. The vaginal delivery at 41.2 weeks was uncomplicated and the healthy baby boy was discharged 3 days later.

In all, 408 maternal cord pairs were tested for HSV-1 antibodies and 323 women $(79.2 \%)$ were seropositive. Although only a small

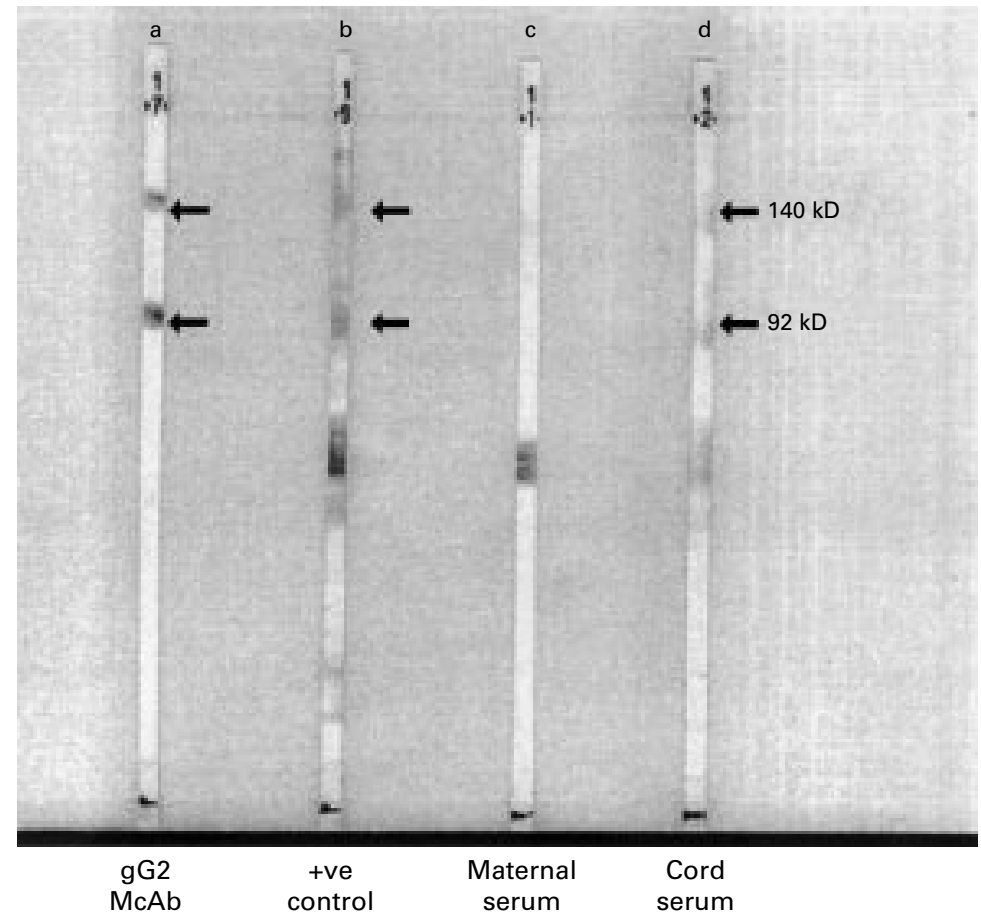

Figure 1 Example of western blot results for one maternal/cord pair. Arrows indicate the presence of bands at $140 \mathrm{kD}$ and $92 \mathrm{kD}$ specific to $\mathrm{HSV}-2 .{ }^{16}$ (a) gG2 specific monoclonal antibody, (b) serum from patient with clinically proved HSV-2 infection. Samples (c) and (d) show a mother/cord pair. (c) Maternal serum sample negative for HSV-2 (no type specific bands). (d) Cord serum sample from baby born to mother c. The appearance of type specific bands in (d) demonstrates a seroconversion to $H S V-2$. number of maternal cord pairs were tested no seroconversions were detected.

\section{Discussion}

Previous studies have suggested that HSV infection in pregnancy is an important public health problem. ${ }^{23671920}$ However, this study shows that in communities with low HSV-2 seroprevalence, HSV acquisition in pregnancy is uncommon $(0.34 \%$ per year) and neonatal herpes is extremely rare. Indeed during the period of the study there was only one case of neonatal herpes out of 13372 deliveries at Westmead hospital (7.5/100 000). This compares with 28.2/ 100000 in Seattle ${ }^{19}$ and 40/100 000 in Atlanta. ${ }^{21}$ The baby with neonatal herpes was born prematurely to a mother who did not participate in the study. The baby was admitted to neonatal intensive care shortly after delivery with respiratory distress and sepsis. HSV-1 was isolated from the urine on day 19.

There were a number of statistically significant differences between women who agreed to participate in the study and those who were not recruited including age, gravidity, country of birth, and whether they were private or public. It is difficult to know whether any of these differences were important. However, as mentioned above the differences in parity and gravidity were as a consequence of a small number of women with multiple previous pregnancies. Age has been shown to be an important factor for the acquisition of HSV-2, with older individuals having a higher HSV-2 prevalence. ${ }^{22}$ However, the actual differences between the groups were small. Indeed, if anything, the differences in country of birth and public or private status probably contributed to a slight overestimation in HSV-2 seroprevalence in this population. Furthermore, an unlinked anonymous study of 300 women who attended consecutively during the period of the study showed a seroprevalence of $12.6 \%$ and this was not significantly different from the main study. We have shown that although the women who participated in the present study were not a completely representative sample of women attending the antenatal clinic at Westmead Hospital, they originated from a variety of ethnic and social backgrounds and included patients from the public and the private sector. In addition, the biological significance of these differences probably is negligible.

There are numerous studies of HSV-2 seroprevalence in pregnancy and these are summarised in table 1. Many of these studies have been small and conducted in selected groups of women. HSV-2 infections have increased in some communities ${ }^{20}{ }^{23}$ but appear relatively static in western Sydney. A study in 1986 with 229 consecutive specimens from antenatal patients using identical laboratory methods showed a prevalence of $14.5 \%,{ }^{11}$ while the current study showed a prevalence of $12.5 \%$.

In Seattle the annualised HSV-2 seroconversion rate was $1.89 \%,{ }^{7}$ in Helsinki it was $1.19 \%,{ }^{24}$ in Stanford $0.58 \%{ }^{13}$ and in our study it was $0.34 \%$. The relation between HSV-2 seroprevalence and the rate of HSV-2 seroconversion in these four studies suggests a positive 
Table 1 HSV type 2 seroprevalence in antenatal clinic attendees

\begin{tabular}{lccll}
\hline City and country & $\begin{array}{c}\text { Number } \\
\text { tested }\end{array}$ & $\begin{array}{l}\text { Percentage } \\
\text { positive }\end{array}$ & Test & Reference \\
\hline Tokyo Japan 1988 & 90 & 6.7 & gG2 Immunoblot & 30 \\
Padua Italy 1985-6 & NK & 8.4 & gG2 Immunoblot & 12 \\
Seville Spain 1985-6 & NK & 9.7 & gG2 Immunoblot & 12 \\
London England 1980-1 & 3553 & 10 & ELISA & 31 \\
Birmingham Alabama USA (whites, private practice) 1985 & NK & 11.4 & gG2 Immunoblot & 12 \\
Sydney Australia 1995-8 & 2616 & 12.5 & gG2 ELISA/WB & Present study \\
Taiwan 1986-7 & NK & 13.5 & gG2 Immunoblot & 12 \\
Sydney, Australia 1984-5 & 229 & 14.5 & gG2 ELISA & 11 \\
Helsinki, Finland 1988-9 & 997 & 16.0 & gG2 ELISA & 24 \\
Stanford USA & 1580 & 16.5 & gG2 ELISA & 13 \\
Stockholm, Sweden 1969 & 941 & 17 & gG2 ELISA & 23 \\
Lyons, France 1986 & NK & 17.3 & gG2 Immunodot & 12 \\
Reykjavik, Iceland 1985 & NK & 18.8 & gG2 ELISA & 12 \\
Malmo, Sweden 1970-3 & 941 & 21 & gG2 ELISA & 32 \\
Malmo, Sweden 1987 & 294 & 21 & gG2 ELISA & 32 \\
Malmo, Sweden 1990-1 & 1190 & 21 & gG2 ELISA & 32 \\
Malmo, Sweden 1986-9 & 562 & 25 & gG2 ELISA & 32 \\
Seattle, USA 1989-93 & 8538 & 28.5 & WB & 6 \\
Stockholm, Sweden 1983 & 1759 & 32 & gG2 ELISA & 23 \\
Stockholm, Sweden 1989 & 1000 & 32 & gG2 ELISA & 23 \\
Stanford, USA 1991 & 277 & 32 & gG2 ELISA & 19 \\
Los Angeles, USA 1985-8 & 1355 & 32 & WB & 14 \\
Atlanta, USA (whites) 1984-5 & NK & 34.9 & gG2 Immunoblot & 12 \\
Sao Paulo Brazil (low and middle class) 1988-9 & 455 & 36 & ELISA and WB & 33 \\
Seattle, USA 1990 & 201 & 37.8 & WB & 15 \\
Sao Paulo, Brazil (very low income) 1988-9 & 200 & 42 & ELISA and WB \\
Atlanta, USA (blacks) 1984-5 & NK & 53.4 & gG2 Immunoblot & 12 \\
\hline & & & 33
\end{tabular}

NK = not known; ELISA = enzyme immunoassay; gG2 = glycoprotein G2; WB = western blot.

^Not type specific.

†Year not stated.

association (see fig $2 ; r=0.912, \mathrm{p}=0.09$ ). Future studies will determine whether this association is maintained and whether it holds over a range of seroprevalence.

One of the important questions raised by this study is why HSV acquisition during pregnancy differs in different communities. There are several possible explanations. Firstly, as discussed above the prevalence of HSV-2 infection in the community may be important. Where HSV-2 infections are more common the likelihood of exposure to the infection is greater. Secondly, sexual behaviour of women and their partners during pregnancy may be an important factor. Women who have multiple partners or whose male partners have sexual intercourse with other women may be at particular risk. Some couples may change their sexual behaviour during pregnancy, perhaps favouring orogenital sex. This may place HSV-1 seronegative women at risk of HSV-1 acquisition. Little is known about sexual behaviour during pregnancy and more detailed information may help determine risk behaviour and establish reason-

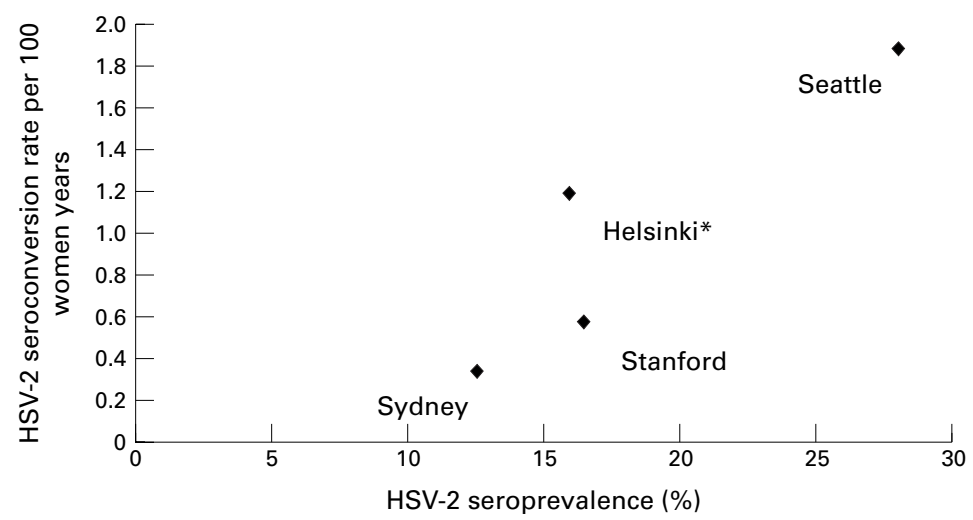

Figure 2 Relation between HSV-2 seroprevalence and seroconversion during pregnancy in Sydney, Stanford, Seattle, and Helsinki. ${ }^{\star}$ The annualised HSV-2 seroconversion rate calculated from five of 840 women who seroconverted over an average of 6 months' follow up. able control strategies. Finally, HSV-1 seroprevalence may be important. Women who are HSV-1 negative may be susceptible both to HSV-1 and HSV-2 during pregnancy. It is of interest that HSV-1 seroprevalence in this community was $79 \%$ in this study and $80 \%$ in $1986^{11}$ compared with $65 \%$ in Seattle.

What control strategies are available and applicable to prevent neonatal herpes? A strategy that has been suggested is use of HSV type specific serology to screen couples considering pregnancy or at the time of the first antenatal visit. $^{719}$ Women with antibodies to HSV-1 and 2 could be reassured about the minimal risk to the baby and advised to tell their obstetrician or midwife about the infection. Where partners are seroconcordant (the same HSV serostatus) the couple could be reassured that the risk to the baby is minimal. However, serodiscordant couples could be counselled about the risk of HSV acquisition and advised to use condoms and avoid cunnilingus (if the man is HSV-1 positive and his partner is not). In addition, the man could consider using antiviral suppression therapy, which has been shown to decrease the frequency of recurrences ${ }^{25-27}$ and viral shedding, ${ }^{28}$ and may reduce the likelihood of transmission. This approach may be welcomed by some couples ${ }^{29}$ but is unlikely to have much public health impact ${ }^{9}$ and in HSV-2 low prevalence populations the costs will probably outweigh the benefits.

In 1993 Randolph and co-workers ${ }^{34}$ developed a model to determine the efficacy, risks, and costs associated with caesarean section for the management of genital herpes in pregnancy. Using the assumptions in this model, we have calculated the cost of serological screening to prevent neonatal herpes in two antenatal settings. The first was a high HSV-2 seroprevalence $(28 \%)$ and high HSV-2 seroconversion in pregnancy setting $(1.89 \%$ per annum) the sec- 
Table 2 Estimated costs of serological screening for HSV-2 in pregnant women and their partners as strategy for preventing neonatal herpes

\begin{tabular}{|c|c|c|c|}
\hline $\begin{array}{l}\text { HSV-2 prevalence in } \\
\text { pregnancy and the risk of } \\
\text { seroconversion during } \\
\text { pregnancy }\end{array}$ & $\begin{array}{l}\text { No of cases of } \\
\text { neonatal } \\
\text { herpes } \\
\text { prevented }\end{array}$ & $\begin{array}{l}\text { Total cost of } \\
\text { screening }\end{array}$ & Cost/case prevented (\$) \\
\hline $\begin{array}{l}\text { Prevalence } 28 \% \\
\text { Seroconversion rate } 1.89 \% \text { * }\end{array}$ & $73(26-135)$ & $\$ 19.21$ million & $263000(142000-739000)$ \\
\hline $\begin{array}{l}\text { Prevalence } 12 \% \\
\text { Seroconversion rate } 0.34 \%^{\star}\end{array}$ & $20(7-38)$ & $\$ 19.85$ million & $992500(522000-2850000)$ \\
\hline
\end{tabular}

\section{^Per million deliveries.}

Assumptions

(1) Calculations based on the probability estimates derived by Randolph et al and HSV-2 seroprevalence and seroconversion rates in Seattle ${ }^{7}$ and Sydney (present study).

(2) Cost of serology $\$ 10$.

(3) Screening costs include screening all women, then screening the partners of all negative women (720 000 men in Seattle and 880000 in Sydney) and finally rescreening all women with positive partners (201600 women in Seattle and 105600 in Sydney).

(4) Strategy will prevent all cases of neonatal herpes.

(5) HSV-2 seroprevalence in male partners is identical to the women

(6) All other costs were excluded including counselling patients with positive serology, increased administration and recall, excess caesarean sections.

(7) Only HSV-2 has been included.

(8) All partners of HSV-2 negative women are tested for antibodies to HSV-2.

(9) All HSV-2 negative women whose partners are HSV-2 positive are retested in late pregnancy

ond a lower HSV-2 seroprevalence (12\%) and lower seroconversion $(0.34 \%)$ population (table 2). Presuming the cost of HSV-2 screening to be $\$ 10$, in the low seroprevalence population, the cost of screening per case of neonatal herpes prevented was $\$ 1240000$ and in the high seroprevalence community it was $\$ 254000$.

Given the association between HSV-2 seroprevalence and the rate of HSV-2 seroconversion in pregnancy, an alternative and cheaper approach would be to conduct regular HSV seroprevalence surveys in women attending antenatal clinics. If seroprevalence to HSV-2 remains low then it is likely that HSV acquisition during pregnancy will not be a major problem. However, if HSV-2 seroprevalence is high or increasing (particularly where HSV-1 serprevalence is relatively low) consideration of the public health measures discussed above may be warranted.

This study was funded by grants from the Ramaciotti Foundation and the Australian National Health and Medical Research Council (954001).

We would like to thank Dr Catherine O'Connor for her assistance at the beginning of the study, Jane Griffith, the nursing and midwifery staff in the antenatal clinics, Jocelyn Ling and Stuart Gilmore for their help in recruiting patients, $\mathrm{Mr}$ Con Tsiavos from the Information Services Division at Westmead Hospital for assistance in data retrieval, and Stig Jeanson for the $\mathrm{gG} 2$ antigen.

Contributors: AM, study idea, protocol design, data analysis and interpretation, report writing; JT, specimen collection and storage, serum assays, report writing, and manuscript review; RT, study coordination, data analysis and interpretation, and report writing; CS, recruitment, specimen collection and report writing; CS, recruitment, specimen collection and
storage, serum assays, and data entry; GB, statistical advice and storage, serum assays, and data entry; GB, statistical advice and
assistance with study design, data analysis and interpretation. assistance with study design, data analysis and interpretation. Manuscript review; KW, recruitment, data entry; JP, recruitment, data entry; CM, database management and statistical
analysis; BT, protocol design, manuscript review; AC, study analysis; BT, protocol design, manuscript review; AC, study
idea, protocol design, supervision of laboratory tests, interpretation of data, and report writing.

1 Whitley R, Arvin A, Prober C, et al. A controlled trial comparing vidarabine with acyclovir in neonatal herpes simplex virus infection. Infectious Diseases Collaborative Antiviral Study Group. $N$ Engl F Med 1991;324:444-4.

2 Nahmias AL, Keyserling HL, Lee FK. Herpes simplex viruses 1 and 2. In: Evans AS, ed. Viral infections of humans. Epidemiology and control. 3rd ed. New York: Plenum, 1989: 393-417

3 Malm G, Berg U, Forsgren M. Neonatal herpes simplex: clinical findings and outcome in relation to type of maternal infection. Acta Paediatr 1995;84:256-60.

4 Garland SM. Neonatal herpes simplex: Royal Women's Hospital 10-year experience with management guidelines for herpes in pregnancy. Aust NZ $\mathcal{F}$ Obstet Gynaecol 1992;32:331-4.
5 Hall SM, Glickman M. Report from the British Paediatric Surveillance Unit. Arch Dis Child 1992;65:807-9.

6 Brown ZA, Vontver LA, Benedetti J, et al. Effects on infants of a first episode of genital herpes during pregnancy. $N$ Engl f Med 1987;317:1246-51.

7 Brown ZA, Selke S, Zeh J, et al. The acquisition of herpes simplex virus during pregnancy. $N$ Engl f Med 1997;337: 509-15.

8 Flemming DT, McQuillan GM, Johnson RE, et al. Herpes simplex virus type 2 in the United States 1976-1994. N Engl f Med 1997;337:1105-11.

9 Mindel A, Estcourt C. Public and personal health implications of asymptomatic viral shedding in genital herpes. Sex Transm Inf 1998;74:387-8.

10 Mindel A. Genital herpes-how much of a public health problem? Lancet 1998 (Supplement, Sexually Transmitted Diseases);351:sm16-sm18

11 Cunningham AL, Lee FK, Ho DWT, et al. Herpes simplex virus type 2 antibody in patients attending antenatal or STD clinics. Med f Aust 1993;158:525-8.

12 Nahmias AJ, Lee FK, Beckman-Nahmias S. Seroepidemiological and sociological patterns of herpes simplex virus infection in the world. Scand F Infect Dis 1983; 69(Suppl):19-36.

13 Arvin AM, Prober CG. Analysis of the epidemiology and pathogenesis of herpes simplex virus (HSV) infections in pregnant women and infants using the HSV-2 glycoprotein $\mathrm{G}$ antibody assay. Infect Agents Dis 1994;2:375-82.

14 Frenkel LM, Garratty EM, Shen JP, et al. Clinical reactivation of herpes simplex type 2 infection in seropositive pregnant women with no history of genital herpes. Ann Intern Med 1993;118:414-18.

15 Brown ZA, Benedetti, JK, Watts DH, et al. A comparison between detailed and simple histories in the diagnosis of genital herpes complicating pregnancy. Am f Obstet Gynecol 1995;172:1299-303.

16 Ho DWT, Field PR, Sjogren-Jansson E, et al. Indirect ELISA for the detection of IgG and IgM antibodies with glycoprotein G (gG2). 7 Virol Methods 1992;36:249-64.

17 Ho DWT, Field PR, Irwing WL, et al. Detection of immunoglobulin $\mathrm{M}$ antibodies to glycoprotein G-2 by immunoglobulin $M$ antibodies to glycoprotein $\mathrm{G}-2$ by
western blot (immunodot) for diagnosis of initial herpes simplex genital infections. F Clin Microbiol 1993;31:315764

18 SPSS. Statistical package for the social sciences [computer program], version 7.0. Chicago, IL: SPSS Inc, 1995.

19 Kulhanjian JA, Soroush V, Au DS, et al. Identification of women at unsuspected risk of contracting primary herpes simplex virus type 2 infections during pregnancy. $N$ Engl 7 Med 1992;326:916-20.

20 Sullivan-Bolyai L, Hull HF, Wilson C, et al. Neonatal herpes simplex virus infection in King County, Washington: increasing incidence and epidemiologic correlates. $\mathscr{F A M A}$ 1983;250:3059-62.

21 Whitley, RJ. Herpes simplex virus infections. In: Remington $\mathrm{S}$, Klein JO, eds. Infectious diseases of the fetus and newborn infant. 3rd ed. Philadelphia: WB Saunders, 1990:282-305.

22 Cowan F, Johnson AM, Ashley R, et al. Antibodies to herpes simplex virus type 2 as a serological marker of sexual lifestyle in populations. BMF 1994;309:1325-9.

23 Forsgren M, Skoog E, Jeansson S, et al. Prevalence of antibodies to herpes simplex virus in pregnant women in Stockholm in 1969, 1983 and 1989: implications for STD epidemiology. Int f STD AIDS 1994;5:113-16.

24 Arvaja M, Lehtinen M, Koskela P, et al. Serological evaluation of herpes simplex virus type 1 and 2 infections in pregnancy. Sex Transm Inf 1999;75:168-71.

25 Mindel A, Weller IVD, Faherty A, et al. Prophylactic oral . Lancet 1984;ii:57-9.

26 Straus SE, Takiff HE, Seidlin M, et al. Suppression of frequently recurring genital herpes. A placebo-controlled, Engl $f$ Med 1984;310:1545-50.

27 Douglas JM, Critchlow C, Benedetti J, et al. A double-blind study of oral acyclovir for suppression of recurrences of genital herpes simplex virus infection. N Engl f Med 1984; 310:1551-6.

28 Wald A, Zeh J, Barnum G, et al. Suppression of subclinical shedding of herpes simplex virus type 2 with acyclovir. Ann Intern Med 1996;124:8-15.

29 Vonau B, Low-Beer N, Barton SE, et al. Antenatal serum screening for genital herpes: a study of knowledge and attitudes of women at a central London hospital. $\mathrm{Br} \mathcal{F}$ Obstet Gynaecol 1997;104:347-9.

30 Hashido M, Kawana T, Tsugemi H, et al. The prevalence of type-specific antibody to herpes simplex virus type 2 in Japan. Igaku-no-ayumi 1990;152:669-70.

31 Ades AE, Peckham CS, Dale GE, et al. Prevalence of antibodies to herpes simplex virus types 1 and 2 in pregnant women, and estimated rates of infection. 7 Epidemiol Commun Health 1989;43:53-60.

32 Persson K, Månsson A, Jönsson E, et al. Decline of herpes simplex virus type 2 and Chlamydia trachomatis infections from 1970 to 1993 indicated by a similar change in antibody pattern. Scand $\mathcal{F}$ Infect Dis 1995;27:195-9.

33 Weinberg A, Canto CLM, Pannuti CS, et al. Herpes simplex virus type 2 infection in pregnancy: asymptomatic viral excretion at delivery and seroepidemiologic survey of two socioeconomically distinct populations in Sao Paulo, Brazil. Rev Inst Med Trop Sao Paulo 1993;35:285-90.

34 Randolph AG, Washington AE, Prober CG. Cesarean delivery for women presenting with genital herpes lesions. Efficacy, risks and costs. $7 A M A$ 1993;270:77-82. 